\title{
Research on the practical cross-curriculum system of product design specialty from the perspective of new engineering
}

\author{
WANG Li, ZHANG Hai-chao \\ Dalian Institute of Science and Technology
}

\begin{abstract}
The traditional economy has transformed into a new economy led by innovation and entrepreneurship, deepened the reform of engineering education and pushed forward the development of "new engineering" as a trend. In the face of "new economy" and "neo-engineering", the applied field of design science is rapidly rising and widening, and the paradigm of design science, teaching idea, intension and talent training mode should be changed. Carrying out the study of the practical cross curriculum system of the major of products design from the perspective of "new engineering", it is mainly discussed from the aspects of curriculum reform, innovation and entrepreneurship education, and directional personnel training between schools and enterprises.
\end{abstract}

\section{The emergence and development of "new engineering"}

\subsection{How "New engineering" produce}

At present, the country drives innovation to drive development, the implementation of "the Belt and Road", "Made in China 2025", "Internet +" and other major strategies, with new technologies, new industries, new models, new industries as the representative of the new economic development, the engineering and technological personnel put forward a higher demand, urgent need to accelerate the reform and innovation of engineering education. The original traditional education model cannot meet the needs of the new economic related fields, and the single ability structure does not conform to the requirement of talents. With the coming of the information age, all kinds of new economy are developing vigorously. The state has formulated and implemented the "The Belt and Road", " China manufacturing in 2025", "Internet plus" and a series of strategies to promote innovation driven economic development, which has put forward new requirements for engineering technology.And the corresponding talents ability and education must also be reformed and innovating.

In order to improve the mismatch of talent supply and demand, the education of "new engineering", which accords with the development of new economy, has emerged. In order to promote the construction and development of "new engineering", the research and practice of "new engineering" is carried out. In February 2017, the Ministry of Education issued the "new engineering" in the Department of Higher learning to carry out the study and practice of the notice, hope that universities around the "new engineering" research and practical activities, so as to deepen the reform of engineering education and promote the construction and development of "new engineering". The research and practice of "new engineering" is a new concept, new structure, new model, new quality and new system of engineering education reform. In order to promote the development of "new engineering course" to match the demand of talent supply and demand, the Ministry of Education issued "Notice on Department of Higher Education of the Ministry of Education Carry Out Research and Practice about "New Engineering Course" "It requires colleges and universities in all regions to carry out the "new engineering" education reform. The education of "new engineering" mainly revolves around the concept, structure, mode, quality and system of engineering education.

\subsection{What is "New engineering"}

There is no clear definition of "new engineering" at present, but the whole society has reached a consensus on the category of "new engineering". "New engineering" is faced with emerging industries, including large data, artificial intelligence, intelligent manufacturing, robotics, cloud computing, and traditional engineering professional upgrading. Compared with traditional engineering, "new engineering" emphasizes the practicality, crossover and comprehensiveness of the subject, especially the close combination of new technologies such as information communication, electronic control, software design and traditional industrial technology. The new engineering course has a higher requirement for the knowledge structure. It emphasizes the practicality and comprehensiveness of various disciplines, especially the application of information communication and electronic technology in traditional industrial technology. 


\subsection{The talent training of "new Engineering"}

In order to adapt to the development of "new engineering", it is the consensus of the whole society to cultivate talent in advance, train the new economy in urgent need of talents, and cultivate the talents with innovative entrepreneurial consciousness, digital thinking and crossborder integration ability. "New engineering" talent not only proficient in a certain discipline, but also should have a knowledge of the integration of interdisciplinary disciplines, they have the ability to learn new knowledge, new technologies to solve future development problems, but also understand the economy, society and management, but also have the humanities. And they are comprehensive talents who are more concerned about society, humanities and art.

To put it simply, the goal of "new engineering" is to train new and innovative talents for new economy. New engineering appears in the new economic transition situation, its education system should also be changed. The difference between the "new engineering" education and the traditional engineering education is that the "new engineering" education promote the innovation and the deep change of the talent training system in many aspects, such as mechanism, idea, curriculum system, training route, quality evaluation standard and enterprise participation degree. Compared with traditional engineering course, the education of the "new engineering course" has put forward higher requirements."New engineering course" pays more attention to the cultivation of practical ability, which makes teaching more docking with enterprises. To strengthen the development of production, teaching and research, we need to reform and innovate teaching ideas, curriculum system, training methods and quality evaluation.

On the whole, the development of new economy calls for the "novel Engineering", and also puts forward new requirements for talent training. "New Engineering" is the general trend, will be to guide the direction of university personnel training, will become the education sector and the community has been the focus of attention.

\subsection{Introduction on the development of "new engineering" in our school}

Dalian University of Science and Technology joined the new Engineering Alliance in March 2018. Our school will use the new education concept, to create new engineering features, through the integration of various disciplines, the Dalian Institute of Science and Technology into a new engineering practical talent training cradle. Our school will create an educational concept that is consistent with the development of "new engineering course" and build Dalian Institute of Science and Technology into a university of training applied talents of "new engineering course". Our school has set up innovation and Entrepreneurship College, Robotics Institute, Ali cloud College and so on, build mobile cloud computing, network security, artificial intelligence, intelligent hardware, such as "new engineering" professional cooperation, training the current emerging industries in the urgent shortage of new talent, practice the implementation of new engineering construction. In the face of the current development of the new engineering education and the vision of our school to build the new engineering Stanford, as well as the new application fields that the design discipline Foundation is facing in the emerging economy, the paradigm of design discipline, teaching idea, intension and talent training mode should be changed. Therefore, under the background of the development of "new engineering" in Dalian Institute of Technology, the product design specialty of Design Art Institute has carried out the research on the reform of the cross-type curriculum system of product design specialty under the new engineering perspective.

\section{Problems and solutions in the education of product design at present}

The problems of the expansion of enrollment scale, the heavy workload of teachers ' scientific research and the emphasis on theory light practice are more prominent. It is necessary to reform and construct the direction of emphasizing the practical innovation ability, strengthening the teaching of professional design practice, and to build the practical cross course system of product design specialty on the basis of realizing the skill training and aiming at the result display and evaluation.

There is a certain gap between the students ' quality and the demand of the enterprise, and the disconnection between the new economy and the new engineering is serious, which reflects the problem of the current training mode. The practical cross curricular system needs to be closely integrated with the design industry. In addition to enabling students to master basic skills in design, it should also be developed to foster students' market thinking. So that their design works can meet the needs of the market and possess commodity attributes.. At the same time, also cultivate students ' vision and creative thinking ability, communication and collaboration ability, self-learning ability, can complete design services and business transformation needs. Through the practice of the cross-curriculum system, to achieve a student-centric, to increase the current economic needs and social needs of the curriculum content, especially the "new engineering" corresponding to the emerging professional, the allocation of interdisciplinary teachers, strengthen the construction of school-enterprise cooperation base. By changing the way of knowledge imparting in traditional classroom teaching and breaking the limitation of time and space in traditional management system, a more open teaching management system is established. This can truly teach students in accordance with their aptitude, so as to meet the needs of students of different levels and characteristics, and to maximize improve the students' ability to learn independently.

\section{The main characteristics of the interdisciplinary and practical teaching}

Interdisciplinary and practical teaching can cultivate students ' ability to analyze and solve problems. In order 
to guarantee the basic teaching requirement, we should turn from teacher-centered to student-centered, break the limitation of time, space and system, set up an open operation management mechanism to meet the students with different levels and different demands, and give full play to students ' autonomy and enthusiasm.

It will rearrange and combine the experimental hours originally dispersed in each course, form an independent and complete project design, carry on the comprehensive evaluation result from classroom report, design report to practice achievement, perfect the integrality of practice course, improve the efficiency and quality of experiment teaching.

We will vigorously carry out cooperation in research and development, cultivate students ' adaptability to society, and let students begin to accept various forms of design training and practical activities in universities. Cultivate the students ' autonomous learning ability and comprehensive practical ability. The practice-type cross course system, can orient the talented person's training and the occupation localization, impels the school and the enterprise the close connection, is divorced from the traditional classroom form, may promote to the design thought innovation also satisfies the enterprise need, may carry on the talented person "the order form" the training, increases the student employment rate Cross-curriculum system to cultivate special creative talents, improve students to cross and practice curriculum characteristics of the design concept and practical ability. The close connection with enterprises can cultivate special talents and make knowledge and ability more practical.

\section{The model of practice-type cross- curriculum system in product design specialty}

\subsection{The cross-course system of product design specialty}

The curriculum content organization and system construction takes the social environment and the economic demand as the direction, constructs "the $1+2+1$ " the teaching platform, guarantees the design science discipline systematic and the science, constructs the curriculum system, 1 year of Design Basic course, 2 year of specialized knowledge and the skill class, 1 year of specialized design curriculum. To increase the richness of the teaching staff, on the basis of the traditional product design teaching team, the interdisciplinary teachers' team and the Enterprise Designer are joined to promote the teachers' teaching, research and practical projects together, and the resources such as scientific. Research and practical projects are integrated to cultivate students' ability to discover and solve problems creatively.

The content of thematic design changed the form of specific product categories in the past. should be linked to social issues, cross-border cooperation to complete the development of new products, for enterprise projects to provide valuable results. The current research problems mainly include information and interactive experience design, health and medical problems design, intelligent products networking Home product design, transportation and travel experience design, cultural products innovation and development and other fields. Combined with the above issues, the curriculum, thematic research, practical curriculum integration, emphasizing the cross cooperation between different professions, strengthen interdisciplinary cooperation, pay attention to design in line with industry needs.

\subsection{The teaching mode of the practice-type cross course of product design specialty}

The teaching mode no longer emphasizes knowledge transfer, but focuses on students, combining teaching with scientific research, so as to achieve mutual benefit in scientific research and teaching activities. Cultivate students ' independent learning, innovative spirit and practical ability.Let teachers' scientific research and teaching be closely integrated, so that they are no longer limited to face to face teaching in class.And it can cultivate students' ability of independent learning and practice

The teaching of curriculum emphasizes inspiration and guidance, let the students out of the classroom facing the society, so that the enterprise designers and industry experts to participate in the design and process of teaching links, to meet the needs of enterprise oriented personnel training, the teaching results and industry docking, the quality of students and industry needs corresponding to the teaching links to achieve interdisciplinary, cross-field, which can let the teaching achievement have the innovation and the social value.

The construction of school-enterprise cooperation base is an important foundation of practical teaching, constructs a complete practice system, establishes the concept of equal emphasis on teaching, scientific research and practice, and allows students to understand social needs and participate in practical projects. Building a school enterprise cooperation platform is a necessary way to combine the scientific research, teaching and practice of teachers. School enterprise cooperation enables students to integrate learning and practice projects, thereby enhancing their in-depth understanding of economic and social needs.Including large data, cloud computing, network security, artificial intelligence, virtual reality and augmented reality, intelligent hardware and other cutting-edge science and technology, the industry's new ideas, new technologies, new knowledge and enterprise needs to integrate into the curriculum system construction. The school-enterprise cooperation can achieve a mutual win.

Through cooperation with the forefront of the field of enterprise, update the content of the course, to provide students with a rich teaching platform. In order to ensure the integrity of the teaching curriculum system, according to the needs of enterprises to train the corresponding ability of talent, directed for the enterprise training highquality personnel, through cooperation with enterprises, to establish long-term research value of the subject content. The purpose of this study is to explore a new 
training mode of talents which is more in line with the new economic environment for the product design profession.

\section{Conclusion}

The practice-type cross course system of product design is combined with the disciplines and specialties of the new engineering, which is advantageous to the interdisciplinary development of multi-disciplinary, and the cooperation with the emerging enterprises is beneficial to the further development of the research, and the competitiveness of the product design professional. This research is a beneficial exploration to the reform of curriculum system and the cultivation of practical talents in product design specialty.

\section{References}

1. Wei Jie. Social Transformation and Design Education Reform: Exploration of "121 Integrated Innovation Talents Training Model" of School of Design, Jiangnan University [J]. Decoration. 7 (2016)

2. Xin Xiangyang. "New areas, new problems, new countermeasures." Lecture on International Conference on Design Education Redesign, (2013)

3. Qi Yongqi. "Design for Activism", "Designing for Transformation", (International Design Education Forum Presentation Record, 2016)

4. Lin Jian. "China's New Engineering Facing the Future". Education Research, Tsinghua University, 3 (2017)

5. Zhong Denghua. Connotation and Action of New Engineering Course Construction. Social Sciences II. Higher Education, 3 ( 2017)

6. Wu Aihua et al. "Accelerating Development and Construction of New Engineering Subjects to Actively Adapt to and Lead a New Economy." Research in Higher Education, 1 (2017) 